\title{
Prevalence and Predisposing Factors to Intestinal Parasitic Infections in HIV/AIDS Patients in Fako Division of Cameroon
}

\author{
Dickson Shey Nsagha ${ }^{1, *}$, Longdoh Anna Njunda ${ }^{2}$, Nguedia Jules Clement Assob ${ }^{2}$, Charlotte Wenze Ayima ${ }^{2}$, \\ Elvis Asangbeng Tanue ${ }^{2}$, Odette Dzemo Kibu ${ }^{2}$, Tebit Emmanuel Kwenti ${ }^{2}$ \\ ${ }^{1}$ Department of Public Health and Hygiene, Faculty of Health Sciences, University of Buea, Buea, Cameroon \\ ${ }^{2}$ Department of Medical Laboratory Sciences, Faculty of Health Sciences, University of Buea, Buea \\ *Corresponding author: nsaghads@hotmail.com,dsnsagha@gmail.com.
}

\begin{abstract}
Background: Understanding the epidemiology of intestinal parasitic infection is essential for the effective management of HIV infection in areas where intestinal parasites are also endemic. Data on the prevalence of intestinal parasitic infection in people living with HIV/AIDS (PLHWA) in Cameroon are sparse. This study was designed to determine the prevalence of intestinal parasitic infections, as well as assess the predisposing factors for the infection in PLHWA in Fako Division of Cameroon. Methods: This was a cross-sectional study conducted between April and July 2014. Stool specimen were collected from consented participants and examined for ova, cysts, larvae or oocytes using the Kato-Katz, Formalin-Ether Concentration, Modified Ziehl-Neelsen and Modified field staining techniques. Statistical analysis performed included the Chi-square test and logistic regression. $\mathrm{P}<0.05$ was considered to be statistically significant. Results: At the end of the study, 300 participants were enrolled, the majority being females $236(78.6 \%)$. The participants were between $21-70$ years (mean $\pm \mathrm{SD}=40 \pm 10)$ of age. The overall prevalence of intestinal parasites was $82.6 \%(95 \% \mathrm{CI}$ : $78.4-87.0)$. The prevalence of infection was associated with age, being more prevalent in the age group 51-60 years $(\mathrm{p}=0.032)$. Intestinal protozoa were more prevalent than intestinal helminthes $(74.3 \%$ vs $11.3 \%)$. The parasites isolated included: Cryptosporidium parvum (44.0\%), Blastocystis hominis (25.0\%), Microsporidium spp. (21.0\%), Entamoeba histolytica (7.3\%), Ascaris lumbricoïdes (4.3\%), Isospora belli (4.3\%), Trichuris trichiura (2.3\%), hookworm (2.7\%), Hymenolepis nana (1.3\%), Strongyloïdes stercoralis (0.7\%), Cyclospora cayetatensis $(3.7 \%)$ and Giardia lamblia $(3.3 \%)$. The predisposing factors for infection with intestinal parasites included poor educational background $(\mathrm{OR}=0.33, \mathrm{p}=0.02)$, unskilled worker $(\mathrm{OR}=0.27, \mathrm{p}=0.04)$, well as a source of drinking water $(\mathrm{OR}=2.6, \mathrm{p}=0.03)$, and living with cats as pets $(\mathrm{OR}=3.06, \mathrm{p}=0.01)$. Conclusion: A very high prevalence of intestinal parasitic infection was observed in PLHWA. Major predisposing factors for intestinal parasites infection included primary level of education, ownership of cats as pets, wells as source of drinking water and having a blue collar job. Routine screening for intestinal parasites should be instituted as part of HIV care in Fako division of Cameroon to improve on the management of HIV.
\end{abstract}

Keywords: HIV, protozoa, helminthes, prevalence, predisposing factors, Fako Division, cameroon

Cite This Article: Dickson Shey Nsagha, Longdoh Anna Njunda, Nguedia Jules Clement Assob, Charlotte Wenze Ayima, Elvis Asangbeng Tanue, Odette Dzemo Kibu, and Tebit Emmanuel Kwenti, "Prevalence and Predisposing Factors to Intestinal Parasitic Infections in HIV/AIDS Patients in Fako Division of Cameroon." Journal Name, vol. 5, no. 3 (2017): 42-49. doi: 10.12691/ajeid-5-3-1.

\section{Background}

Intestinal parasites are highly endemic in Sub-Saharan Africa [1], a region which is currently experiencing the highest burden of HIV/AIDS [1]. With the overlap in the distribution of both diseases, co-infection with one or more intestinal parasites and HIV is therefore common in the region [2]. The incidence of Intestinal parasitic infections is approximately $50 \%$ in developed countries whereas it reaches up to $95 \%$ in developing countries [2]. Cameroon is among the Sub-Saharan African countries with an overlapping high rate of HIV and intestinal parasitic infections. The prevalence of intestinal parasitic infection observed in Cameroon ranges from 27.9\% reported by Lehman et al. [3] in Douala (in the Littoral region) to $57.48 \%$ reported by Marius et al. [4] in Yaounde (in the Centre region). Information on the prevalence of parasitic infections and HIV coinfection are not readily available from the other regions of the country.The presence of opportunistic parasites such as Cryptosporidium parvum, Cyclospora cayetanensis, Isospora belli and Microsporidia are well documented in patients with HIV/AIDS [5]. Non opportunistic parasites such as Entamoeba histolytica, Giardia lamblia, Trichuris 
trichura, Ascaris lumbricoides, Strongyloides stercoralis and Ancylostoma duodenale are frequently encountered in developing countries but are not currently considered opportunistic in HIV/AIDS patient [6]. Many factors have contributed to the increase and reinvasion of newly emerging intestinal parasites including the increasing migration of people due to political instability, war, economical problems, and travel to developing countries [7]. Also poverty and malnutrition are some of the factors that contribute to concomitant infections of both HIV and intestinal parasites in Sub-Saharan Africa [8].

The link between intestinal parasites and HIV/AIDS is thought to be bidirectional, with the presence of concomitant infections skewing the immune response of the host towards predominantly a type- 2 immune response (Th2) as well as an increase in the immune system activation $[9,10,11]$. The presence of chronic immune activation and a dominant Th2 immune response may increase the host susceptibility thereby promoting HIV infection and disease progression $[12,13,14]$. On the other hand, the progressing development of AIDS in HIV is a risk factor for the acquisition of other infective agents including parasites which are the proximate cause of death of AIDS patients $[15,16,17]$. The effect of intestinal parasites on the HIV RNA levels is not clear either with reports suggesting that treatment of intestinal parasitic infections may reduce HIV RNA levels [18].

Whatever the outcome may be of intestinal parasitic and HIV co-infection, it is obvious that co-infection between these pathogens is common particularly in developing countries where the factors favoring transmission of parasites are all in place This negatively impacts on the health status and outlook of people living with HIV/AIDS [19]. Understanding the actual burden of intestinal parasites in HIV is therefore imperative in improving on the management of HIV/AIDS.

The objectives of this study performed in Fako division of the South West region was to i) determine the prevalence of intestinal parasitic infection in people living with HIV/AIDS in the region, and ii) assess the predisposing factors for infection with intestinal parasites in the target group.

\section{Materials and Methods}

\subsection{Study Area}

This is part of the study conducted on "Intestinal parasitic infections in HIV/AIDS patients attending treatment centers in Fako-Division Cameroon: prevalence and predisposing factors" at the Faculty of Health Sciences, University of Buea, Cameroon. The other part of the study has been reported elsewhere [20]. Briefly, participants were enrolled in the HIV treatment centers in the Regional Hospital of Buea and Limbe found in Buea and Limbe respectively. Buea and Limbe are the two major urban centers in Fako division in the South West Region. These two HIV treatment centers are the only two centers in Fako serving the entire population of Fako. Limbe is the head quarter of the Cameroon Development Corporation (CDC), one of the largest employers in Cameroon after the government. These two towns attract people from other parts of the country for work, education or leisure. With a prevalence of $8 \%$, the south west region has one of the highest HIV prevalence in the country [21].

\subsection{Study Design and Setting}

This was a hospital based cross-sectional study in which participants of the Buea and Limbe Regional Hospitals HIV treatment centers were enrolled between April and July 2014.

\subsection{Sampling Technique}

A time limited sampling technique was used, where patients were consecutively recruited into the study. Participants were enrolled into the study provided they gave their consent and met the inclusion criteria.

\subsection{Study Population}

HIV patients greater than or equal to 21 years (according to Cameroon's cut-off age for adulthood) attending the HIV treatment centers of the Regional Hospitals in Buea and Limbe were approached to take part in the study. Participants were selected based on whether they met the inclusion criteria HIV patients irrespective of their ages and gender were eligible to participate. Patients were randomly recruited into the study from these treatment centers until sample size of 313 was attained from April to July 2014. Although there was a respondent rate of $95 \%$, up to 8 participants filled questionnaires with the investigator and provided only blood samples but did not provide stool samples while the remaining 5 provided stool samples, incomplete questionnaire information and no venipuncture. Thus a total sample size of $n=300$ participants was attained. Excluded from the study were individuals that were on any anti-parasitic medication. Children were also excluded from the study due the low prevalence of HIV in this age group.

\subsection{Study Variables}

The study participants were grouped as follows: Urban or rural location, those with $\geq 21$ years, their level of education, their occupation (blue collar and white collar jobs): Blue-collar jobs (Participants who do manual work with hands) and white-collar jobs (participants who do work which do not involve manual labour) and personal/environmental hygienic practices.

\subsection{Data Collection}

\subsubsection{Administration of Questionnaire}

The data collection has been described elsewhere [20]. Briefly, a self-administered structured paper based questionnaire was issued to consented participants to obtain information on the socio-demographic, medical history and potential risk factors related to food-borne, waterborne, person-to-person, and zoonotic transmission of intestinal parasites. The questionnaires were explained in Pidgin English to those to those who were not literate. The participants guided on how to answer the questionnaire 
and were expected to summit the completed questionnaire prior to specimen collection.

\subsection{Specimen Collection}

The participants were provided with a wide open neck, clean and sterile container to provide stool specimen. The participants were instructed on how to produce stool specimen and also to take it to the laboratory within $1 \mathrm{hr}$ of time of collection.

\subsection{Analysis of Stool Specimen}

Stool specimens were analysed using the Kato-katz and formol ether concentration techniques, and smears were examined using the modified field and modifies Ziehl-Neelsen staining techniques.

Formol ether concentration technique: Using an applicator stick, about one gram of stool was emulsified in about $7 \mathrm{ml}$ of $10 \%$ formol water in a screw-cap tube. The proceeding was done as described by Cheesbrough [22]. In this techniques we were able to detect both protozoa cysts, oocysts and helminthes eggs. Also this technique has as prediction to concentrate protozoa cysts, oocysts and helminthic eggs.

Kato-Katz Technique: Fresh stool samples were analyzed by the kato-katz technique for the qualitative and quantitative detection of helminthes eggs [22].

Smears prepared from the formol ether concentration techniques were stained using the Modified field staining technique for the detection of spores of Microsporidium species [23], and the Modified Ziehl-Neelsen staining technique for the detection of oocysts of Cryptosporidium species, Isospora belli, and Cyclospora cayetanensis [24].

\subsection{Ethical Considerations}

Ethical Clearance was obtained from the Institutional Review Board of the Faculty of Health Sciences of the University of Buea. Administrative authorization was obtained from the South West Regional Delegation of the Ministry of Public Health and the District Health Service. The purpose of the study alongside the role of the participants were well explained in the consent form to the participants in English, French and the local Pidgin English languages and participation could only take place after the participant had read and signed the informed consent form voluntary.

\subsection{Statistical Analysis}

Data were analysed using SPSS Version 20.0. Armonk, NY: IBM Corp. Statistics performed included the Chisquare test for group comparison and the logistic regression analysis for the measure of association. P-value less than 0.05 considered as statistically significant at $95 \%$ confidence interval (CI). Where appropriate the Fisher exact test was used to determine p-values.

\section{Results}

By the end of the study, 300 participants successfully summited completed questionnaire and stool specimen. Among them were $21.3 \%$ males and $78.6 \%$ females. The ages of the participants ranged between 21-70 years (mean $\pm \mathrm{SD}=40 \pm 10)$. Majority of the participants were from rural $54 \%$ than urban $46 \%$ settings.

The overall prevalence of intestinal parasitic infection in HIV/AIDS patients observed in this study was $82.6 \%$, 95\% CI: 78.4 - 87.0. Intestinal protozoa were more prevalent than intestinal helminthes [74.3\% vs. $11.3 \%$ ]. The most common parasitic infection was Crptosporidium parvum 44\%, while the least prevalent was Strongyloides stercoralis $0.7 \%$ (Figure 1).

In this study, the prevalence of intestinal parasitic infection was higher in females $84.3 \%$ than in males $76.5 \%$ (Figure 2). However this difference was not observed to be significant $(\mathrm{p}=0.14)$. The prevalence of intestinal parasites was higher in HIV/AIDS patients resident in rural areas $84.4 \%$ than those residing in urban centers $80.5 \%$ (Figure 2). But the difference was not statistically significant $(\mathrm{p}=0.54)$. The prevalence of intestinal parasites was highest in the age group 51 - 60years $(90.3 \%)$ (Figure 2). A significant association was observed in the prevalence of intestinal parasites with age $(p=0.032)$.

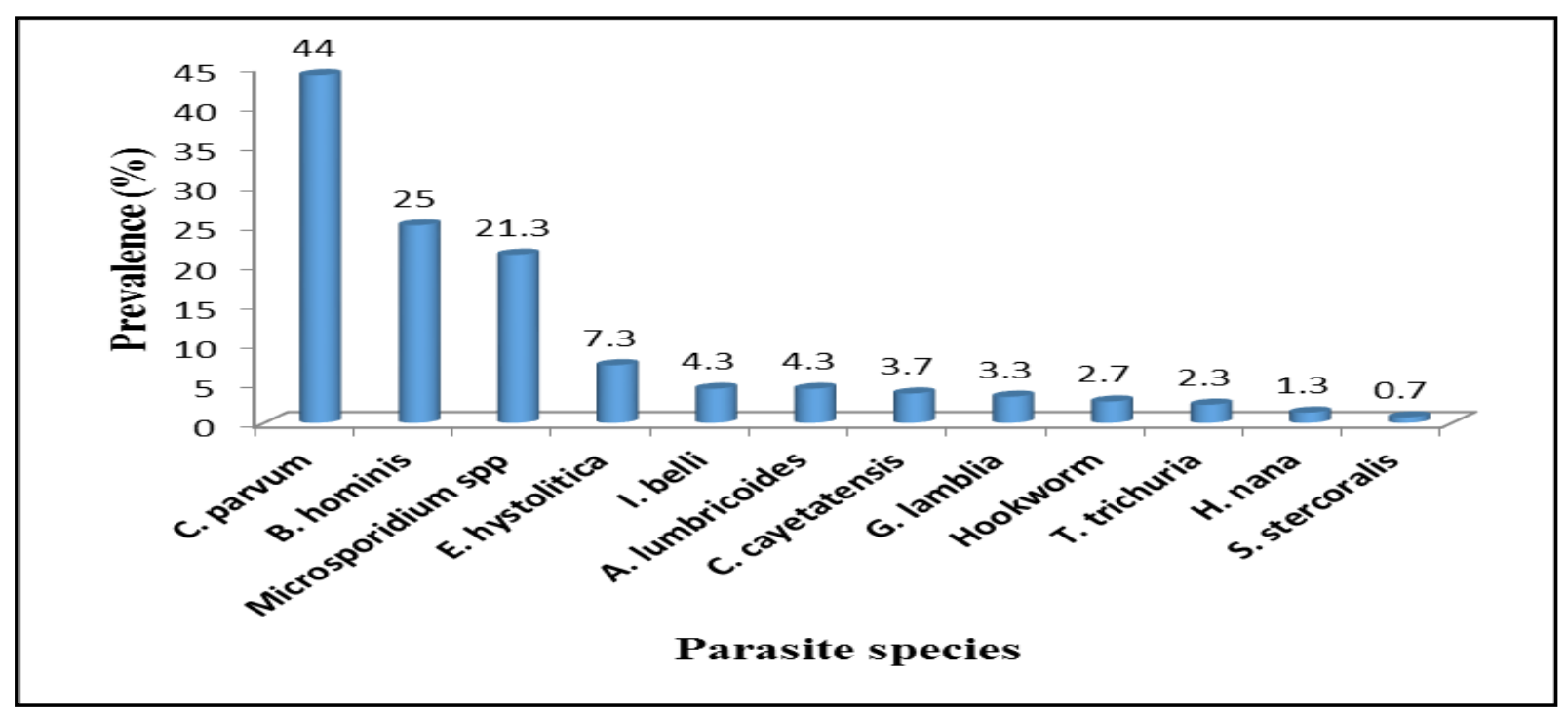

Figure 1. Prevalence of Intestinal Parasites in the HIV/AIDS patients from April to July 2014 
Predisposing factors for the infection with intestinal parasites included: the level of education, being common in HIV patients with primary education or less $(\mathrm{p}=0.02)$, unskilled profession ( $\mathrm{p}=0.04)$, wells as a source of drinking water $(p=0.03)$, and the presence of cats as pets $(\mathrm{p}=0.01)($ Table 1$)$.

Table 1. Predisposing factors for intestinal parasitic infections among HIV patients in Fako Division $(n=300)$

\begin{tabular}{|c|c|c|c|c|c|}
\hline Demographic variables & $\begin{array}{l}\text { Number Examined } \mathrm{n}(\%) \\
\mathrm{N}=300 \\
\end{array}$ & $\begin{array}{l}\text { Number infected with any parasites } \\
\mathrm{n}(\%)\end{array}$ & COR & $95 \% \mathrm{CI}$ & P-values \\
\hline \multicolumn{6}{|l|}{ Gender } \\
\hline Male & $64(21.3)$ & $49(76.5)$ & 1 & & - \\
\hline Female & $236(78.7)$ & $199(84.3)$ & 0.607 & $0.308-1.194$ & 0.14 \\
\hline \multicolumn{6}{|l|}{ Location } \\
\hline Urban & $139(46.3)$ & $112(80.5)$ & 1 & & - \\
\hline Rural & $161(53.7)$ & $135(84.4)$ & 0.798 & $0.44-1.44$ & 0.45 \\
\hline \multicolumn{6}{|l|}{ Age group } \\
\hline $21-30$ & $45(15.0)$ & $36(80.0)$ & 1 & & - \\
\hline $31-40$ & $118(39.3)$ & $99(83.9)$ & 0.76 & $0.31-1.85$ & 0.55 \\
\hline $41-50$ & $90(30.0)$ & $71(78.8)$ & 1.07 & $0.44-2.60$ & 0.88 \\
\hline $51-60$ & $31(10.3)$ & $28(90.3)$ & 0.42 & $0.10-1.73$ & 0.33 \\
\hline $61-70$ & $16(5.3)$ & $14(87.5)$ & 0.57 & $0.11-2.98$ & 0.71 \\
\hline \multicolumn{6}{|l|}{ LEVEL OF EDUCATION } \\
\hline Tertiary & $20(6.7)$ & $13(65)$ & 1 & & - \\
\hline Secondary & $111(37.0)$ & $92(82.8)$ & 0.38 & $0.13-1.08$ & 0.06 \\
\hline$\leq$ primary & $169(56.3)$ & $143(84.6)$ & 0.33 & $0.12-0.92$ & 0.02 \\
\hline \multicolumn{6}{|l|}{ OCCUPATION } \\
\hline Students & $12(4.0)$ & $7(58.3)$ & 1 & & - \\
\hline White collar & $231(77.0)$ & 193(83.5) & 0.27 & $0.08-0.91$ & 0.04 \\
\hline Blue collar & $40(13.3)$ & $34(85.0)$ & 0.24 & $0.05-1.04$ & 0.09 \\
\hline Unemployed & $17(5.7)$ & $14(82.3)$ & 0.30 & $0.05-1.63$ & 0.21 \\
\hline \multicolumn{6}{|l|}{ INCOME LEVELS (FRS) } \\
\hline$>\mathbf{5 0 0 0 0}$ & $80(26.7)$ & $62(77.5)$ & 1 & & - \\
\hline$<\mathbf{5 0 0 0 0}$ & $220(73.3)$ & $186(84.5)$ & 0.62 & $0.33-1.19$ & 0.15 \\
\hline \multicolumn{6}{|c|}{ PERSONS PER HOUSEHOLD } \\
\hline$<5$ & $152(50.7)$ & $123(80.9)$ & 1 & & - \\
\hline$\geq 5$ & $148(49.3)$ & $125(84.5)$ & 1.28 & $0.70-2.33$ & 0.41 \\
\hline \multicolumn{6}{|c|}{ SOURCE OF DRINKING WATER } \\
\hline Pipe borne & $247(82.3)$ & $206(83.4)$ & 1 & & - \\
\hline Well & $23(7.7)$ & $15(65.2)$ & 2.60 & $1.06-6.73$ & 0.03 \\
\hline Stream & $30(10.0)$ & $27(90.0)$ & 0.55 & $0.16-1.92$ & 0.43 \\
\hline \multicolumn{6}{|l|}{ PRESENCE OF TOILET } \\
\hline Private Water closet & $57(19.0)$ & $44(77.2)$ & 1 & & - \\
\hline Private pit latrine & $128(42.7)$ & $108(84.3)$ & 0.62 & $0.28-1.36$ & 0.24 \\
\hline Public pit latrine & $111(37.0)$ & $94(84.6)$ & 0.61 & $0.27-1.37$ & 0.23 \\
\hline Open field(no toilets) & $4(1.3)$ & $2(50)$ & 3.38 & $0.43-26.4$ & 0.22 \\
\hline \multicolumn{6}{|c|}{ HAND WASHING HABIT Before Eating } \\
\hline Always & $84(28.0)$ & $68(80.9)$ & 1 & & - \\
\hline Sometimes & $143(47.7)$ & $123(86.0)$ & 0.69 & $0.33-1.42$ & 0.31 \\
\hline Never & $73(24.3)$ & $57(78.0)$ & 1.19 & $0.54-2.59$ & 0.65 \\
\hline \multicolumn{6}{|l|}{ SOURCE OF FOOD } \\
\hline Home cooked food & $167(55.7)$ & $143(85.6)$ & 1 & & - \\
\hline Road side foods & $39(13.0)$ & $30(76.9)$ & 1.78 & $0.75-4.22$ & 0.18 \\
\hline HCF+RSF & $94(31.3)$ & $75(79.7)$ & 1.50 & $0.77-2.93$ & 0.22 \\
\hline \multicolumn{6}{|l|}{ PRESENCE OF PETS } \\
\hline None & $220(73.3)$ & 184(83.6) & 1 & & \\
\hline Dogs & $56(18.7)$ & $49(87.5)$ & 0.73 & $0.30-1.74$ & 0.47 \\
\hline Cats & $24(8.0)$ & $15(62.5)$ & 3.06 & $1.24-7.54$ & 0.01 \\
\hline \multicolumn{6}{|l|}{ ANIMAL REARING } \\
\hline None & $149(49.7)$ & $117(78.5)$ & 1 & & - \\
\hline Goats & $46(15.3)$ & $42(91.3)$ & 0.34 & $0.11-1.04$ & 0.05 \\
\hline Fowls & $68(22.7)$ & $58(85.2)$ & 0.63 & $0.28-1.37$ & 0.24 \\
\hline Pigs & $34(11.3)$ & $29(85.2)$ & 0.63 & $0.22-1.75$ & 0.37 \\
\hline Rabbits & $3(1.0)$ & $2(66.6)$ & 1.82 & $0.16-20.8$ & 0.52 \\
\hline
\end{tabular}

$\mathrm{CI}=$ Confidence Interval; $\mathrm{COR}=$ Crude Odd Ratio. 


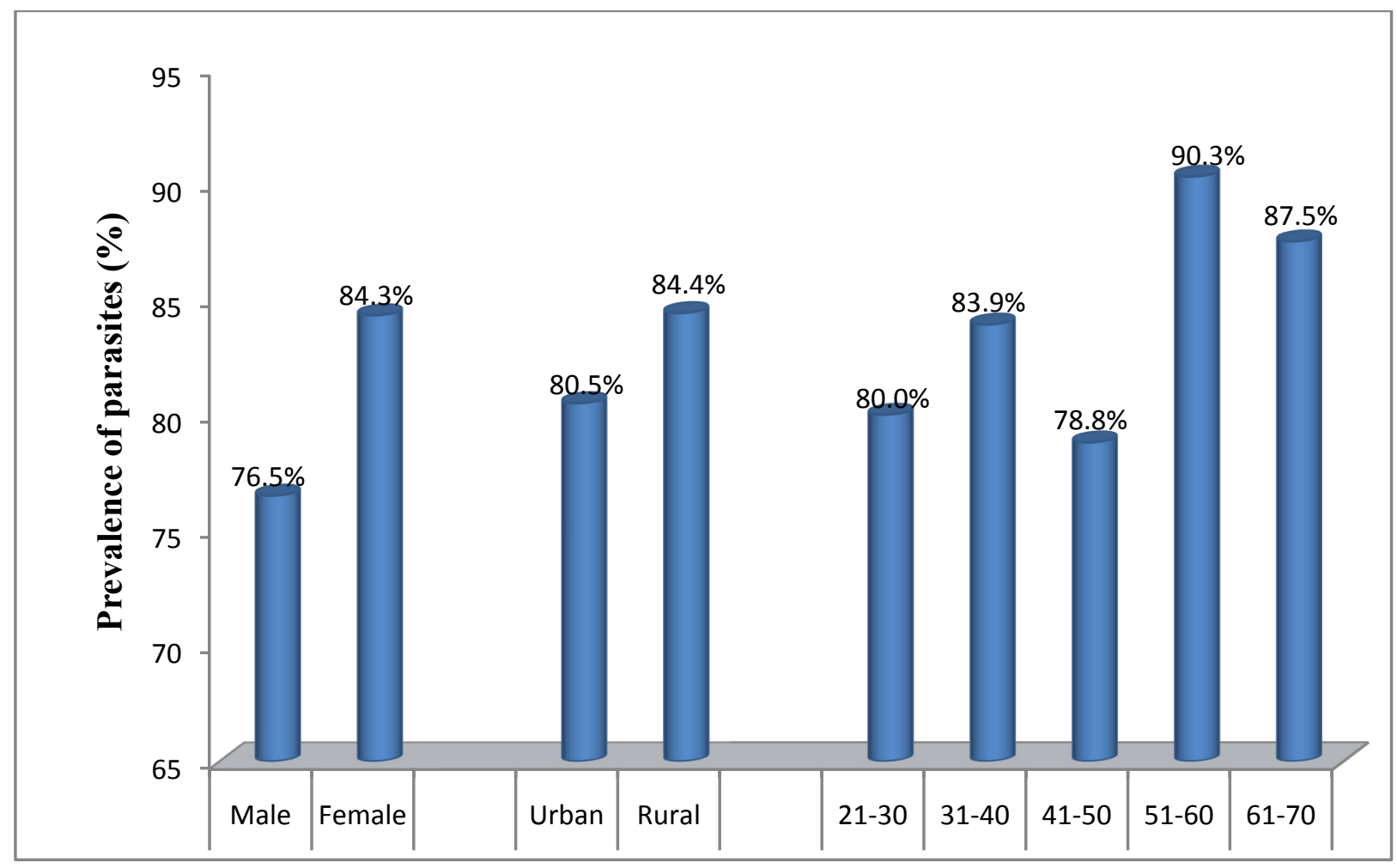

Figure 2. Intestinal parasites in study participants based on gender, age and location in HIV/AIDS patients Fako Division, Cameroon

\section{Discussion}

There is a high burden of parasitic infections in Fako Division in the South West Region of Cameroon. The interaction between HIV and other infective agents including parasites have long been recognised to adversely influence the health status of people living with HIV/AIDS. Understanding the epidemiology of intestinal parasitic infection is essential for the effective management of HIV infection. Data on the prevalence of intestinal parasitic infection in people living with HIV/AIDS in Cameroon are sparse. Overall, a prevalence of $82.6 \%$ was observed in this study, which is higher compared to the $27.9 \%, 33 \%$, and $57.48 \%$ observed in studies performed elsewhere in Cameroon by Lehman et al. [3], Sarfati et al. [25], and Marius et al. [4] respectively. The differences in the prevalence reported in these studies and the present study could be attributed to the difference in the methodology. In this study, intestinal parasites were isolated using the formol ether concentration and the kato-katz techniques in addition to methods involving staining with the modified field stain and the modified Ziehl-Neelsen stain meanwhile the other studies performed elsewhere at best involved the use of only one concentration and one staining technique. The prevalence of intestinal parasites was also high compared to that reported in other countries, $27.9 \%$ in Apulia, Italy [26] and the $28.1 \%$ and $42.9 \%$ observed in Abuja and Abeokuta respectively in Nigeria [27]. However, the prevalence observed in this study was similar to the $81.8 \%$ reported in Tanzania [28] and the $79.3 \%$ in Osun state of Nigeria [29].

In this study, the prevalence of intestinal parasites was higher in females $(84.3 \%)$ than in males $(76.5 \%)$. However, the difference was not observed to be statistically significant $(\mathrm{p}=0.14)$. This finding is similar to other studies performed elsewhere $[7,26,28]$. This could be explained in that females are the ones more engaged with domestic chores and farming which exposes them to intestinal parasites. Contrary to this, is a study performed in Nigeria in which the prevalence was observed to be higher in males than in females [30]. This may be due to differences in the study area, study population and the activities of these males which expose them than the females. A significant association was observed between the prevalence of intestinal parasites and age $(p=0.032)$, with the prevalence being higher in the age group 51-60 year. This is in accordance with a study performed in Nigeria [31]. This high rate in patients above 50 years could be attributed to the immunosuppression due to the presence of HIV/AIDS coupled to the weakened immune system associated with ageing.

In this study, intestinal protozoa $(74.3 \%)$ were more prevalent that intestinal helminthes $(11.3 \%)$. The prevalence of intestinal protozoa observed in this study was lower compared to the $80.8 \%$ reported in Kenya [32]. Protozoa infection varies per location and hygienic practices differences in prevalence may be also due to differences in study population. The prevalence of intestinal helminthes observed in this study was lower compared to the $37.04 \%$ observed in Ethiopia [8], but higher than the prevalence reported by Njunda et al. [33] in Yaounde-Cameroon. Soil transmitted helminthes is very common with children. However, children were not included in our study as with other studies which explains the difference in the prevalence of intestinal helminthes. The most prevalent intestinal protozoa was Cryptosporidium parvum (44\%) meanwhile Ascaris lumbricoides (4.3\%) was the most prevalent helminthes. The prevalence of Cryptosporidium parvum was higher than that reported elsewhere in Cameroon [3,4,25]. Cryptosporidium parvum is mostly associated with unclean drinking water sources. Shortage of drinking water supply is common in the study area. 
Hence, this promotes use of unclean drinking water sources by the inhabitants thus, further predisposes them to this parasite especially in the immunocompromised individual.

Predisposing factors for infection with intestinal parasites observed in this study included the level of education, the prevalence was observed to be higher in individuals with only primary education. Ostan et al. [34] had demonstrated the relationship that exists between increasing level of education and decreasing incidence of intestinal parasites. Other factors included the occupation of the individual whereby the prevalence was observed to be higher in unskilled workers which confirms the findings of Assefa et al. [8]. The source of drinking water was also significant risk factors for the infection, with intestinal parasites more common in individuals who used water from wells for drinking. This finding is similar to that reported in Ethiopia [35]. This could be attributed to the poor quality of the wells which are often not dug very deep due to the stony nature of the terrain in the study area and as such are easily contaminated by sewage and runoff. Ownership of cats as pets was also observed to be a significant risk factor for infection with intestinal parasites. The plausibility of Cryptosporidium being passed from cats to humans has been suggested in a few earlier studies. For example, in 1983 Koch et al. [36] described cryptosporidiosis in an immunocompromised patient whose cat also harbored Cryptosporidium oocysts. Similarly, Egger et al. [37] reported a case in which an 8-year-old boy contracted cryptosporidiosis during a visit to a farm; Cryptosporidium oocysts were found in a cat but not in the investigated calves on the farm, and thus the authors suggested that the cat was the source of infection. However, neither of these cases was confirmed by molecular methods. Another case of unusual zoonotic Cryptosporidium transmission has been described from Peru [38]. In a recent study, the HSP70 sequences from the cat and the patient were $100 \%$ identical to each other $(1,885 / 1,885 \mathrm{bp})$, but identical sequences were also found in most of the other investigated C. felis isolates from cat and humans [39].

In this study, rearing of domestic animals was not observed to be a predisposing factor for infection with intestinal parasites which is unusual owing to the fact that people in the study area especially in the rural settings are farmers, rearing animals such as goats, rabbits, chicken etc. Thus they come in contact with their lither thereby exposing them to infection with intestinal parasites. This finding is contrary to studies performed elsewhere $[40,41,42,43]$. Studies using molecular techniques are required in the area to investigate the presence of zoonotic transmission of intestinal parasites.

Although this study provides data on the actual burden of intestinal parasitic infections in people living with HIV/AIDS in Fako Division which could impact the management of HIV in the area, it was subject to several limitations. Firstly, the result only represent people living with HIV/AIDS in Fako Division and may not be generalized to all HIV - infected persons in Cameroon. Secondly the questionnaires used to determine the risk factors for intestinal parasites was self-administered which could have affected the accuracy in determining the predisposing factors for the transmission of intestinal parasites in the study population. However to minimize this, questions and benefits of the study were well explained to the participants prior to response.

\section{Conclusion}

A high prevalence of intestinal parasites was observed in people living with HIV/AIDS in Fako division of Cameroon. A significant association was observed between the prevalence of intestinal parasites with age, being more prevalent in individuals between the ages of $51-60$. Overall, Cryptosporidium parvum was observed to be the most prevalent intestinal parasite meanwhile Ascaris lumbricoides was the most prevalent helminthes infection. The major predisposing factors for infection with intestinal parasites included having a poor educational background, ownership of cats as pets, use of wells as a source of drinking water and being blue collar workers. Intestinal parasitic infections are still huge burden in HIV/AIDS patients in the Fako Division. This implies parasitic coinfections in HIV/AIDS individual should not be neglected whether they are symptomatic or asymptomatic. Continues screening and public health surveillance systems should be put in place to combat this dilemma. In addition to the health talks by health care providers on anti-retroviral therapy, talks on basic hygienic practices should be enhanced. There should be a continuous surveillance of intestinal parasites in HIV/AIDS patients to check changes in the fauna of infection for proper laboratory testing and management of these patients. Due to the importance of knowledge on microorganisms implicated in infectious diarrhea and on the individual and collective impact of infection, there is a need for more studies on this subject especially at the molecular level.

\section{List of Abbreviations}

$\begin{array}{ll}\text { ARV } & \text { Antiretroviral } \\ \text { ART } & \text { Antiretroviral Therapy } \\ \text { HIV/AIDS } & \text { Human Immunodeficiency Virus/Acquired } \\ & \text { Immunodeficiency syndrome } \\ \text { IPIs } & \text { Intestinal parasitic infections } \\ \text { PLHIV } & \text { People living with HIV } \\ \text { HAART } & \text { Highly Active Antiretroviral Therapy } \\ \text { VCT } & \text { Voluntary counseling and testing } \\ \text { WHO } & \text { World Health Organization } \\ \text { EPG } & \text { Egg per gram }\end{array}$

\section{Acknowledgements}

The authors wish to thank the Director, doctors, nurses and the laboratory staff of the Regional Hospitals in Buea and Limbe for making this work a success by allowing us to use their patients and in data collection. Our sincere gratitude also goes to the patients who freely gave their consent to take part in this study.

\section{Conflict of Interest}

The authors declare that they have no competing interest. 


\section{References}

[1] UNAIDS (2012). Global Report: UNAIDS Report on the Global AIDS Epidemic 2012. Geneva, Switzerland.

http://www.unaids.org/en/media/unaids/contentassets/documents/e pidemiology/2012/gr2012/20121120_UNAIDS_Global_Report_2 012_with_annexes_en.pdf.

[2] Adamu $\mathrm{H}$, Petros B Intestinal protozoan infections among HIV positive persons with and without Antiretroviral Treatment (ART) in selected ART centers in Adama, Afar and Dire-Dawa, Ethiopia. Ethiop. J. Health Dev. 2009; 23: 133-140.

[3] Lehman L, Kangam L, Nguepi E, Mbenoun M, Bilong Bilong C. Study of intestinal parasitic infections associated with HIV infection in Douala, Cameroon. J Infect Dev Ctries. 2012; 7(2): 137-143.

[4] Marius Z., Patrice E., Claire V., Carine N: Prevalence of Intestinal Parasites among HIV patients at the Yaounde Central Hospital, Cameron. The Pan African Medical Journal. 2014; 18:136.

[5] Lekha, T., Anil, K.G., Shyam, S. and Tribhuban, M. Correlation between CD4 counts of HIV patients and enteric protozoans in different seasons- An experience of a tertiary care hospital in Varanasia (India). BMC Gastroent. 2008; 8:36-39.

[6] Mohandas, K., Sehgal, R., Sud, A. and Malla, N. Prevalence of intestinal parasitic pathogens in HIV seropositive patients in Northern India, Jpn J Infect Dis. 2002; 55(3): 83-84.

[7] WHO. Prevention and control of Intestinal parasitic infections. WHO Technical Report. 1987; 749: 1-86.

[8] Assefa, S., Erko, B., Medhin, G., Assefa, Z. and Shemilis, T. Intestinal parasitic infections in relation to HIV/AIDS status, diarrhoea and CD4 T-cell count. BMC Infectious Diseases 2009; 9: 155-162.

[9] Kalinkovich A, Weisman Z, Greenberg Z, Nahmias J, Eitan S, Stein M, Bentwich Z. Decreased CD4 and increased CD8 counts with $\mathrm{T}$ cell activation is associated with chronic helminth infection. Clin Exp Immunol 1998; 114: 414-21.

[10] Bentwich Z, Kalinkovich A, Weisman Z, Borkow G, Beyers N, Beyers AD. Can eradication of helminthic infections change the face of AIDS and tuberculosis? Immunol Today 1999; 20: 485-7.

[11] Clerici M, Declich S, Rizzardini G. African enigma: key player in human immunodeficiency virus pathogenesis in developing countries? Clin Diagn Lab Immunol 2001; 8: 864-6.

[12] Shapira-Nahor O, Kalinkovich A, Weisman Z, Greenberg Z, Nahmias J, Shapiro M, Panet A, Bentwich Z: Increased Susceptibility to HIV-1 infection of peripheral blood mononuclear cells from chronically immune activated individuals. AIDS 1998, 12: 1731-1733.

[13] Kalinkovich A, Borkow G, Weisman Z, Tsimanis A, Stein M, Bentwich Z: Increased CCR5 and CXCR4 Expression in Ethiopians Living in Israel: Environmental and Constitutive Factors. Clin Immunol 2001, 100 (1):107-117.

[14] Secor WE, Shah A, Mwinzi PM, Ndenga BA, Watta CO, Karanja DM: Increased density of Human Immunodeficiency Virus type 1 co-receptors CCR5 and CXCR4 on the surfaces of CD4+ T cells and monocytes of patients with Schistosoma mansoni infection. Infect Immun 2003, 71:6668-6671.

[15] Morris A, Lundgren JD, Masur H, Walzer PD, Hanson DL, Frederick T, Huang L, Beard CB, Kaplan JE: Current epidemiology of Pneumocystis pneumonia. Emerg Infect Dis 2004, 10: $1713-1720$.

[16] Ramakrishnan K, Shenbagarathai R, Uma A, Kavitha K, Rajendran R, Thirumalaikolundusubramanian P: Prevalence of intestinal parasitic infestation in HIV/AIDS patients with diarrhea in Madurai city, south India. Jpn J Infect Dis 2007, 60: 209-210.

[17] Nielsen NO, Friis H, Magnussen P, Krarup H, Magesa S, Simonsen P: Co-infection with subclinical HIV and Wuchereria bancrofti, and the role of malaria and hookworms, in adult Tanzanians: infection intensities, CD4/CD8 counts and cytokine responses. Trans R Soc Trop Med Hyg 2007, 101: 602-612.

[18] Wolday D, Mayaan S, Mariam ZG, Berhe N, Seboxa T, Britton S, Galai N, Landay A, Bentwich Z. Treatment of intestinal worms is associated with decreased HIV plasma viral load. J Acquir Immune Defic Syndr 2002; 31: 56-62.

[19] Frederico F, Haendel, Busatti G, Valeria L, Joseph F G Santos, and Maria A Gomes. High prevalence of enteroparasitosis in urban slums of Belo Horizonte-Brazil. Presence of enteroparasites as a risk factor in the family group. Pathog Glob Health. 2013; 107(6): 320-324.

[20] Nsagha DS, Njunda AL, Assob JCN, Ayima CW, Tanue EA, kibu OD, Kwenti TE. Intestinal Parasitic Infections in relation to CD4+ T Cell Counts and Diarrhea in HIV/AIDS Patients with or without Antiretroviral Therapy in Cameroon. BMC Infectious Diseases. 2016; $16: 9$.

[21] National AIDS Control Committee (2010). The Impact of HIV and AIDS in Cameroon through 2020.

http://www.healthpolicyinitiative.com/Publications/Documents/12 50_1_Cameroon_EN_Singles_Reduced_acc.pdf.

[22] Cheesbrough M. District Laboratory Practice in Tropical Countries (Second edition, Part 1), Cambridge. 2006; 178-235.

[23] Cheesbrough, M. District Laboratory Practice in Tropical Countries. 2005, 3Rd ed., part 1, pp. 178-215. Cambridge University Press, United Kingdom.

[24] Henriksen S, Pohlenz J. Staining of Cryptosporidia by a modified Ziehl-Neelsen technique. Acta Vet Scand. 1981; 22: 594-596.

[25] Sarfati, C., Bourgeois, A., Menotti, J., Liegeois, F., Moyou-Somo, R., Delaporte, E., Dero uin, F., Ngole, M. and Molina, J. Prevalence of intestinal parasites including Microsporidia in Human Immunodeficiency virus-infected adults in Cameroon: A cross-sectional study. Am. J.Trop. Med. Hyg; 2006; 74(1): 162-164.

[26] Brandonisio O, Maggi MA, Lisi A, Anriola A, Acquafredda A, Angarano G. Intestinal protozoa in HIV-infected patients in Apulia, South Italy. Epidemiol Infect. 1999; 123: 457.

[27] Udeh EO, Goselle ON, D-Popova DD, Abelau M, Popov TV, Jean N., David J. S. The prevalence of intestinal protozoans in HIV/AIDS patients in Abuja, Nigeria. Sci World J. 2008; 3: 14.

[28] Gomez, M., Atzoric, L., Rossi, P., Scalgia, M. and Pozio, E. Opportunistic and non-opportunistic parasites among HIV positive and negative patients with diarrhoea in Tanzania. Trop Med.1996; 46(2), 109-114.

[29] Moura H, Fernandes O, Viola JPB, Silva SP, Passes RH, Lima DB Enteric parasites and HIV infection: occurrence in AIDS patients in Rio de Janeiro, Brazil. Mem Inst Oswaldo Cruz.1989; 84: 527.

[30] Wiwanitkit V. Intestinal parasitic infections in Thai HIV-infected patients with different immunity. BMC Gastroenterol. 2001; 1: 1 .

[31] Babatunde SK, Salami AK, Fabiyi J P, Agbede OO, Desalu OO. Prevalence of intestinal parasitic infestation in HIV seropositive and seronegative patients in Ilorin, Nigeria. Ann Afr Med 2010; 9: 123-8.

[32] Cornelius KK., Robert S., Rose., Prevalence of Intestinal parasitic infections among HIV patients in Baringo, Kenya. Pan Afr Med J.2012; 13: 37.

[33] Njunda A.L., Assob N.J.C., Nsagha S.D., Nde F.P., Kamga F.H.L., Asangbeng T.E., and Kwenti E.T. (2012). Low Prevalence of Helminth infection among HIV patients in Cameroon. Research and Reviews: Journal of Microbiology and Biotechnology; 1(1): 611.

[34] Ostan D, Kilimciogu A, Girginkardesler N, Oeyurt B, Limoncu E, and Okru.2007.Health Iniquities : Lower Socio-economic Conditions and higher Incidences of Intestinal Parasites. BMC Public Health 7:342.

[35] Zelalem MT, Abebe G, Mulu A. Opportunistic and other intestinal parasitic infections in AIDS patients, HIV sero-positive healthy carriers and HIV sero-negative individuals in Southwest, Ethiopia. East Afr J Public Health. 2008; 5: 169-73.

[36] Koch KL, Shankey TV, Weinstein GS, Dye RE, Abt AB, Current WL, et al. Cryptosporidiosis in a patient with hemophilia, common variable hypogammaglobulinemia, and the acquired immunodeficiency syndrome. Ann Intern Med 1983; 99: 337-40.

[37] Egger M, Nguyen XM, Schaad UB, Krech T. Intestinal cryptosporidiosis acquired from a cat. Infection 1990; 18: 177-8.

[38] Xiao L, Cama VA, Cabrera L, Ortega Y, Pearson J, Gilman RH. Possible transmission of Cryptosporidium canis among children and a dog in a household. J Clin Microbiol 2007; 45: 2014-16.

[39] Jessica B, Linda T, Rickard E, Karin T, Jadwiga WK and Marianne L. Possible zoonotic transmission of Cryptosporidium felis in a household. Infection Ecology and Epidemiology. 2015, 5: 28463.

[40] Adesiji YO, Lawal RO, Taiwo SS, Fayemiwo SA, Adeyeba OA. Cryptosporidiosis in HIV infected patients with diarrhea in Osun State, Southwestern Nigeria. Eur J Gen Med. 2007; 4:119-22.

[41] Faye B, Tine RC, Ndiaye JL, Kintega c, Mange NM, Snowps and Gaye S. Impact of Intestinal Parasites on Intensity of HIV 
infections in Senegal. Journal of Antiviral and Antiretroviral therapy 2010; 1: 011-012.

[42] Ortega, Y.R., Sterling, C.R. and Gilman, R.H. Cyclospora cayetanenesis. Advances in Parasitology.1998; 40: 399-418. S24-S27.
[43] Al-Delaimy AK, Al-Mekhlafi HM, Nasr NA, Sady H, Atroosh WM, et al. Epidemiology of Intestinal Polyparasitism among Orang Asli School Children in Rural Malaysia. PLoS Negl Trop Dis. 2014; 8(8): e3074. 